Jennifer Lock, UNIVERSITY OF CALGARY, jvlock@ucalgary.ca

Jacqueline Rainsbury, UNIVERSITY OF CALGARY, jacqueline.rainsbury@gmail.com

Tracey Clancy, UNIVERSITY OFCALGARY, tclancy@ucalgary.ca

Patricia Rosenau, UNIVERSITY OF CALGARY, PROSENAU@ucalgary.ca

Carla Ferreira, UNIVERSITY OF CALGARY, mcferrei@ucalgary.ca

\title{
Influence of Co-teaching on Undergraduate Student Learning: A Mixed-Methods Study in Nursing
}

\begin{abstract}
Co-teaching has been explored in the field of education but is a relatively new phenomenon in higher education. Its benefits and challenges are well documented; however, what is lacking is substantive evidence highlighting the influence of co-teaching amongst undergraduate students. Particularly, in practice-based professions like teaching, nursing, and social work, active participation in collaborative teams is more the norm than the exception. Undergraduate students need to have opportunities to learn how to be collaborative, as well as observe modeling of collaborative teaching practice. In the article, we report on a two-year mixed-methods research study that investigated students' and instructors' experiences with co-teaching in a Nurse as Educatorcourse. The findings from three cohorts engaged in the research suggest co-teaching to be an effective teaching and learning strategy. However, for co-teaching to be a positive experience for both students and instructors, purposeful scaffolding and supports need to be in place. Also outlined are recommendations for higher education with regard to designing and modeling co-teaching practice.
\end{abstract}

\section{KEYWORDS}

Co-teaching, collaborative teams, experiential learning, nursing, higher education

\section{INTRODUCTION}

Today's nurses work in complex situations where they are active members of teams. As part of this work, they teach patients, colleagues, or teams of health care providers. Often times nurses' approaches to their roles as educators are informed by how they have received information in the pasttheir experience of being taught. The educator role within nursing practice is essential in providing quality care and improved health outcomes; however, in practice, engaging in patient teaching is often done in private where particular practices may go unchallenged or unexamined. Similar to nursing practice, nurse educators engage in teaching students in isolation either in large lecture halls or small classrooms and labs. As a practice profession that privileges experiential learning as key to any teaching and learning encounter, opportunities to observe and learn from each other are critical in preparing nurses for the world beyond the nursing program. This article asserts that the experience of being cotaught, and then co-teaching, influences students' understanding of how they learn and how they can apply what they learned in preparation for professional practice.

The purpose of this article is threefold. First, we establish what co-teaching is, and outline 
current practices and challenges of co-teaching within the context of higher education. A specific focus is on the influence of co-teaching on undergraduate nursing student learning. Second, we report on a course where students in their final year in a Nursing program experience being co-taught and engage in co-teaching. Findings are shared from a two-year mixed-methods research study that examined students' and instructors' experiences with co-teaching. The study involved three cohorts of a Nurse as Educator course. Third, drawing on the literature and the data, recommendations for co-teaching practice in higher education are offered.

\section{CO-TEACHING}

In higher education, faculty members may be collaborators in research, but collaborators in teaching or being co-teachers is less commonplace. Co-teaching (sometimes known as team teaching) in higher education is defined as "two or more individuals who come together in a collaborative relationship for the purpose of shared work... for the outcome of achieving what none could have done alone" (Wenzlaff et al., 2002, p. 14). This collaborative relationship creates new opportunities for different ways to engage in curriculum design, planning, and teaching. Co-teaching supports the potential for the creation of a strong learning community for students and instructors, and benefits students and instructors both pedagogically and professionally (Ferguson \& Wilson, 2011). Plank (2011) argued that students observing "their teachers learn from each other and even disagree with each other models for students how scholars and informed citizens within a community of learning can navigate a complex and uncertain world" (p. 5). In this article, co-teaching is defined as involving two instructors who collaboratively design and simultaneously teach and assess student work within a semester.

Co-teaching is complex. Rytivaara and Kershner (2012) noted that co-teaching is "a genuinely peer-learning relationship in which communication shifts between different contexts within and beyond the classroom" (p. 1001). Effective co-teaching requires instructors to learn to work with each other, to trust each other, and to be responsive to each other and to the learning environment (Laughlin, Nelson, \& Donaldson, 2011). Ongoing, open communication is a necessity both in terms of the development of the relationship, but also in the day-to-day teaching practice. There is a need to develop trust so as to allow for rich dialogue, as well as to accommodate discussions about what is working, but also to address what is not working and why.

\section{Co-teaching in higher education}

Co-teaching has been examined in a number of studies over the past 40 years relative to nursing programs. In a qualitative, descriptive study, Shephard and Ashley (1979) found that nursing students at a Canadian university strongly favored team teaching because it made lectures more challenging. Twelve years later, Minardi and Riley (1991) evaluated a team teaching strategy used in a communication skills course for Registered Mental Health Nurse students in the United Kingdom. In written feedback, students noted that lectures were more engaging and interesting when taught by more than one instructor, and that the teachers acted as professional role models for students. In a Canadian study, Dumas (1999) used post-course instructor debriefing to determine advantages and disadvantages of team teaching in nursing education. The instructors noted the following advantages for students: different points of view offered, enlarged knowledge base, different role models, teamwork, and evaluation that is more objective. That is, the strategy of co-teaching prepares nursing students to face different perspectives in professional values and it expands their knowledge base. Furthermore, 
observing teachers interacting with one another provides a model for students on how to enter into professional relationships and to manage differences in values and opinions while maintaining mutual respect and openness. In a more current study, students enrolled in the Bachelor of Science in Nursing program at the University of British Columbia viewed team teaching positively and supported it as a learning strategy (Mislang, 2011). They specifically noted that it challenged student learning, increased teacher credibility, provided nursing role models, and promoted student learning. In this review of coteaching in nursing over the past few decades, it is evident that there are specific advantages to student learning through a co-teaching practice.

A key advantage of co-teaching is to reflect the nature of the professional community of practice in which students begin to engage during their undergraduate program. Trained nurses participating in a continuing professional development course on ethical decision making supported the team teaching method used and noted several benefits (Kerridge, Kyle, \& Marks-Maran, 2009). These benefits include hearing different perspectives, the enhancement of group work, and the development of cognitive skills. Co-teaching prepares students to enter professional relationships and to navigate their complexity.

Not all co-teaching or team teaching experiences are positive. An earlier study examined student perceived advantages and disadvantages of co-teaching. The students identified the following as disadvantages: repetitive or overlapping material; instructors contradicting each other; and personality conflict between instructors (Floyd, 1975). Minardi and Riley (1991) found that students in their study also pointed to the possibility of confusion and the potential for instructors' conflict being transmitted to students. These findings also support Dumas (1999), who found that students experienced stress or insecurity due to instructors' differences of opinion. Awareness of these potential challenges must be addressed for the benefits of co-teaching not to be hindered or impeded.

Co-teaching impacts student learning. Kruszeski and colleagues (2009) used a variety of methods in their evaluation of collaborative teaching strategies in an accelerated Bachelor of Nursing program. Instructors participated in focus groups and stated that students' projects demonstrated knowledge and skills related to evidence-based nursing protocol. Students' completion of performance scales resulted in mean scores well above the expectations for competency in evidence-based practice. Students also reported a high level of satisfaction with their shared clinical project, and staff felt a greater connection to students due to the collaboration.

From the literature, it is evident that co-teaching, while not without challenges, presents numerous advantages to student learning and outcomes in higher education. It cannot be assumed that co-teaching always results in a student experience that will positively influence learning and the development of their professional practice. Rather, through purposeful design and thoughtful rolemodeling of co-teaching, students are able to observe and experience the benefits. Further, by giving students the opportunity to practice co-teaching, they will develop a greater understanding of what is required, as well as how this can be used in their future practice. One way this can be achieved is through designing and facilitating an experiential learning approach.

\section{FROM THEORY TO PRACTICE}

Kolb's (1984) cycle of experiential learning defines learning as the "process whereby knowledge is created through the transformation of experience" (p. 41). The learning cycle encompasses four learning modes: concrete experience, abstract conceptualization, reflective observation, and active experimentation. The learner experiences a four-stage recursive cycle of learning, in which immediate or 
concrete experiences provide a basis for observations and reflection. These observations and reflections translate into abstract concepts producing new implications for action, which are actively tested, thus creating new experiences.

Kolb's (1984) cycle of experiential learning formed the foundation of the Nurse as Educator course in which students gain an understanding of the abstract concepts of teaching and learning, engage in reflective observation, and then apply their understanding in co-teaching experience in a lab context. The subsequent reflection of the experience is translated into further action and experimentation in the classroom setting. Kolb and Kolb (2005) stated that "all learning is relearning" (p. 194) facilitated through a process that draws out the students' beliefs about a topic so that they can be examined, tested, and integrated with new, refined ideas. The process of learning is enhanced by the movement, back and forth, between reflection and action, and feeling and thinking.

\section{COURSE CONTEXT}

The Nurse as Educator course (NURSING 503.42) is a 13-week Bachelor of Nursing seniorlevel course where nursing students explore the principles of teaching and learning in relation to their evolving nursing practice. Grounded in Kolb's experiential learning model, students witness and experience co-teaching as a pedagogical approach. Through observation, the nature of co-teaching is role modeled to students by two faculty nurse educators teaching the course. The role modeling provides students with an example of how to enter into professional relationships, manage differences in values and opinions while maintaining mutual respect and openness, and engage in shared leadership. Throughout the course, students are invited to reflect on the experience of being co-taught and apply their knowledge of teaching and learning through purposefully designed course assessments or assignments. The first assessment illustrates students' understandings of the course content through the design and demonstration of a health education session within a nurse-patient relationship. In pairs, students present and debrief what an effective health education session looks like that is grounded in the principles of teaching and learning. This three-part assignment allows students to experience and demonstrate that effective teaching and learning require purposeful planning, implementation, evaluation, and reflective practice.

The second assessment continues to build on students' experiences of co-teaching; however, in this assessment, students engage in peer education where they co-teach a three-hour nursing lab involving their junior peers. Much like the first assessment, this teaching and learning experience is scaffolded. Starting with observing nurse educators teaching their junior peers, students reflect on the foundational components of the course and what they are seeing, hearing, and feeling in the classroom setting. In pairs, the students then create and deliver their lesson plan in consultation with their course instructors as well as the nurse educator they shadowed.

The final assessment involves students' written reflections on their teaching opportunities and experiences in the course, feedback from peers, and exploration of the literature. This assignment challenges students to articulate their values, beliefs, and foundational philosophy that support their professional teaching practice, including their insights into the influence that the co-teaching environment has on their competence and leadership development in the educator role. 


\section{METHODOLOGY}

A mixed-method research design (Creswell, 2012) was implemented to investigate the following question: What impact does co-teaching in a nurse education course have on the development of professional practice?

Ethics approval was received to conduct the study from the University's Conjoint Faculties Research Ethics Board. The study was conducted over three semesters when the Nurse as Educator course was delivered between 2014 and 2015. This course was offered in the first semester of the final year of the Nursing program. All undergraduate students in the three offerings of the course $(n=65)$ were invited to participate in the study. Nine $(n=9)$ students gave informed consent to participate in the study. Over the three offerings of the course, three instructors $(n=3)$ participated in this study. One of the three co-teaching instructors taught the course in all three semesters. A second instructor co-taught the course twice and the third only once. A member from the research team met with the class to explain the study and to distribute the informed consent forms. Students and the co-teaching instructors were not aware of who was in the study. Only aggregated data were shared with members of the research team after the course completion.

Three data sources were used to address the question, and providing the opportunity to triangulate the findings. First, the 20- to 30-minute individual interviews occurred with students at the end of the course and again four months after. A member of the research team, who was not an instructor of the course, conducted the interviews. Student and instructor questions were similar but taken from their respective perspectives. For example, students were asked such questions as the following to learn of their experiences with co-teaching and the impact it had on their own practice: From your experience, how has the co-teaching influenced the learning environment and your own learning; What are some strengths of co-teaching; What are some challenges of co-teaching; and Drawing on your experience of being co-taught last semester, how has that learning been translated into your professional practice?

The second data source came from the instructor interviews, which were 25 to 30 minutes in length. The following were examples of their questions: How did you make co-teaching happen; What were the strengths of how you modelled co-teaching practice to your students; and Given your own coteaching, what were some of the challenges you had along the way?

Third, attributes and impact of co-teaching were examined from relevant course documents (e.g., course outline, assignment descriptions, completed assignments) obtained from both students and instructors. Students provided the research team with two pieces of coursework: 1) the peer education assignment that focused on the teaching synthesis of their own co-teaching, and 2) the scholarly teaching philosophy paper. To maintain anonymity, two members of the research team who were not co-teachers collected the assignment data.

First and second cycles of coding occurred using Saldaña's (2013) two-stage process for qualitative research. In the first cycle, codes were assigned by using key phrases from interview questions (e.g., strengths, challenges, and influence of the co-taught course on leadership capabilities). The second cycle method involved pattern coding as "a way of grouping those summaries into smaller number of categories, themes, or constructs" (Miles, Huberman, \& Saldaña, 2014, p. 86). This analysis involved looking for repetition of the words or phrases by the participants that led to the development of patterns (Miles et al., 2014). The data was hand-coded by one member of the research team. Following the coding, members of the research team then reviewed the coded data. 


\section{RESULTS AND DISCUSSION}

Drawing on the data from the first and second interviews with students, the instructor interviews and the student artifacts from two assignments, attributes, and the impact of co-teaching are discussed. First, we begin by sharing the participants' understanding of co-teaching and key attributes. Second, data are discussed with regard to how the students experienced co-teaching. Third, we examine the impact the co-teaching experience (course and assignments) had on learning as reported by students. Fourth, drawing from their experience as reported in the second interview and from their peer teaching synthesis, findings are shared in terms of how this has transferred to their professional practice.

\section{Attributes of co-teaching}

Student and instructor participants were asked in the first interview to describe co-teaching and its attributes. The students described co-teaching as being two instructors teaching the same class or section of students. They spoke of it as a partnership and working together in collaboration. As noted by one instructor,

\section{It is a job that no one person can do and hence co-teaching is where two or maybe even more people come together to not just divide the task but to work together to achieve a common goal.}

For the students drawing on their experience in the Nurse as Educator course and from other experiences being co-taught, they identified the following five attributes of co-teaching: 1) Need to have open communication between instructors to support effective cooperation and collaboration; 2) To be good planners who are aware of what each other will teach; 3) Need for a respectful and open professional relationship that allows the strengths of each to come through in the classroom setting; 4) Different perspectives and discipline areas foster a fuller picture of the content being taught; and 5) Pedagogical relationships foster shared leadership roles and encourage each other's participation. The diversity of knowledge and experience that each brings to the teaching relationship leads to a fuller picture of what is being taught.

The three instructors shared similar attributes when describing co-teaching. However, they emphasized the need for a complementary relationship. This relationship is nurtured through a commitment that is grounded on a respectful recognition of the exchange among the instructors and a lack of competitiveness. According to one instructor, it is a "relational endeavor that requires some prior understanding of each other's approach to teaching, philosophy of teaching, and principles of teaching." Further, the instructors were very aware that the nature and dynamics of a co-teaching relationship were dependent on the instructors. As noted by another instructor, "co-teaching with different people sometimes manifests itself in different ways; it brings out different strengths." As such, the co-teaching instructors need to learn about each other's teaching philosophy and styles and then work together in developing a fluid and responsive relationship that supports students' learning.

Findings from our study regarding the characteristics and advantages of co-teaching parallel those reported in the literature. Instructors debriefed post-course in Dumas' 1999 study echoed our instructors' views on the importance of teamwork and role modelling and the benefits to students of offering different perspectives. Likewise, student views from our study are in line with those reported elsewhere and point to co-teaching resulting in greater student participation and learning, especially when co-teachers model a respectful and collaborative relationship in the classroom (Minardi \& Riley, 1991; Mislang, 2011). 


\section{How students experienced co-teaching}

In the field of health care, there is great emphasis placed on working collaboratively and this expectation can be daunting for some learners. As one student alluded in her experience of co-teaching with a peer, she felt challenged to

... trust my partner...I was worried that I may offend my co-teacher by interrupting her and back tracking, and I did not want the learners to feel like we were incompetent.

This speaks to the vulnerability of co-teaching as experienced by a student; hence, it is critical to provide an exemplar and establish an experiential space that engenders mutual respect and collaboration when engaging in a co-teaching relationship. By offering students several opportunities to observe the relationship and experience a co-taught environment, instructors were deliberate in creating a classroom setting that fostered openness, congeniality, and collaboration. As one student commented about the instructors, "I loved the camaraderie they both had together." Students acknowledged the commitment and passion the instructors had for the content and for teaching together:

The two of them are so passionate about what they're doing and the material they're teaching that probably contributes to a more positive learning environment for everyone.

There was recognition from all participants of the importance of communication processes that invited ideas and sharing. Through the instructors' dialogues and actions towards each other, they modeled the process of inviting in the other person's voice and honoring what each contributes to the discussion. The open nature of co-teaching displayed for the students how to ask and pose questions in a respectful manner. "They (the instructors) enable more sharing that way and it helps the class become comfortable with sharing. It takes away the disequilibrium between teacher and learner." Kruszeski et al. (1999) echoed this in their study on collaborative teaching strategies, where one of the advantages was a closer connection between staff and students.

From the data, three key elements emerged in terms of the students' appreciation of the role modeling they experienced through co-teaching. First, there was a valuing of differences and different pedagogical approaches. From observing the different knowledge, skill sets, and experiences the two instructors brought to the learning, the students developed a greater appreciation of the differences and saw them as a strength. Diversity of teaching styles, expertise, knowledge, and pedagogy were seen within the lens of being valuable and being complementary.

Second, students witnessed co-teaching practice in the formal learning environment, which could then be used in their professional contexts. One student indicated:

Seeing how it can be done in a university style or level and with our assignments seeing how we can work together as co-teachers and model [instructors' names] and draw on each other's strengths to add additional knowledge into our teaching sessions.

Another student noted, “They're able to bounce ideas off of each other so they're able to shape the environment in a way that one instructor may not be aware of." 
Third, through the modeling, students developed an appreciation for how different perspectives can be shared in respectful and thoughtful ways that enhance the learning experience. Through the good exemplars demonstrated by the co-teaching instructors, the students became more comfortable in reflecting on their own practice that was reported in their peer-teaching reflections and in their second interviews. This appreciation and understanding of role modelling is supported by the benefits that trained nurses perceived of co-teaching in a continuing education context, i.e., hearing different perspectives enhanced group work and aided in the development of cognitive skills (Kerridge et al., 2009). This appreciation of diversity of values, philosophies, and experiences has been seen as a strength for some time as evidenced in the Floyd (1975) study.

One of the assignments for the course required students to prepare a lesson, co-teach it to junior peers, and reflect on the experience. From this co-teaching experience, they appreciated that something better can come from collaboration compared to what can be achieved by an individual. As described by one student:

Co-teaching would enable each other's participation, so being aware when the other has something to say and paying attention to their cues. Playing off of each other's strengths and experience since each may have an example that's very relevant to the content of what's being taught.

\section{Impact of the experience of co-teaching on learning}

Engaging in co-teaching meant that students ought to be reflexive. Not only were students asked to apply theoretical principles of teaching and learning through their peer education experience, but they were also explicitly probed to think about how entering a co-teaching relationship impacts their way of being as they learn about what it means to take on the role of educator as a novice nurse. One student's reflection identified his way of being as a learner discovering co-teaching with a peer. In his reflection, he spoke of being respectful throughout the process: "I will respect my colleague to teach with his/her own teaching methods and I will collaborate to develop an organized lesson plan." He also anticipated potential issues that may arise during the co-teaching experience and the need to have an open frame of mind: "my colleague may be better at presenting certain factors than I"; "my partner will have differing perspectives than I, and will understand that collaboration is something that is highly regarded in these situations."

Another student commented on how the co-teaching relationship allowed for reflective practice, which is critical in the teaching and learning process:

In terms of my own learning, I was able to identify my own strengths and weaknesses through the co-teaching. It was reflected back to me after our session. We talked about it and debriefed about it and it gave me a chance for self-reflection on what I could have done better and kind of see my partner as an example, as a role model that I could take after.

These examples demonstrate the type of thinking that needs to occur in support of not only a healthy co-teaching partnership but also one's development as a lifelong learner. It highlights the appreciation for what the other person brings to the co-teaching relationship as well as how to work respectfully with each other. 
One student's reflection on the peer education experience recognized the developmental and social nature of learning and co-teaching as a teaching strategy:

Reflecting on the co-teaching aspect, it was beneficial for the class to have two peer leaders to provide two distinct sets of experiences and expertise. It was quite an interesting experience to be co-taught within the course and translating those techniques that our professors used into my own practice. I truly value the opportunity of growing into another role of the nurse as an educator and am looking forward to continue developing my skills in the future.

Dumas (1999) concluded that the strategy of co-teaching prepared students to face different perspectives in professional values and expanded their knowledge base and ultimately taught them how to enter into professional relationships and manage differences in values and opinions while maintaining mutual respect and openness.

\section{Transfer to practice}

After the students completed the Nurse as Educator course, they enrolled in a senior preceptored practicum the following semester that involved completing 378 hours of clinical practice in preparation for their transition as a graduate nurse/registered nurse role. In the final interview after their preceptor placement, students shared how their experience with being co-taught informed or influenced their professional practice. The experience of being co-taught in an interactive learning environment (i.e., Nurse as Educator course) that engaged students through experiential learning assignments provided opportunities to develop their competence and confidence, which in their preceptor placement resulted in them feeling more self-assured to interact with other health care providers. There was a shift in who they co-taught with yet they carried with them the principles of engaging in co-teaching to inform their working relationships whether it was with their preceptors or other members of the health care team. One student shared her experience during her final practicum where she worked in an interprofessional team, particularly with a dietitian, and she recognized that each of them brought forth different expertise in the care and management of patients with diabetes:

In my own personal practice, say working with a dietitian, I know a lot about nutrition for diabetics but that is her area of expertise so Ilet her take the lead on that. If we're talking about $A 1 C$ values she is aware of that but I take the role because it's more of my expertise. It's a version of what [instructors' names] did so successfully last semester.

The development of confidence resulted in the students taking on different attitudes or a different way of being.

The opportunity to observe co-teaching as role modeled by the instructors in the course as well as the chance to practice co-teaching through one of the learning assessments helped one student assimilate and accommodate learning of co-teaching as an approach to see a different perspective when working collaboratively within inter-professional teams to support patient centered care to improve health outcome: 
Being able to work with another colleague or someone else, a multidisciplinary team to kind of teach a patient together. Let's say a physiotherapist wanted the patient to do a certain stretch and I can understand what the physiotherapist is trying to teach. I can help the patient reach that goal since the physiotherapist won't always be there. I'm the nurse, I'll be there... we may not be teaching together at the same time but at different parts of the day. It's splitting up the teaching.

As students' nursing knowledge, skills, and attitudes expanded along with the potential influence of coteaching gained through experiential learning as an approach that may underpin patient care, they were then in a better position to advocate for the patient.

Through the nursing courses along with their practicum, students were developing a greater sense of lifelong learning. Being in a profession requires students to identify as a nurse in the program and to embrace ongoing learning as part of their professional development and commitment. The ability to question and reflect on one's own learning is a key element in being a successful learner. Through the experience of co-teaching, students were encouraged to be more open to discussing with their preceptors how to work through differences in their approaches to teaching and learning. The following quote demonstrates one student's confidence in communicating how she liked to learn:

I was able to let my preceptor know how I learn. We had a good learning relationship. The same thing as colleagues because sometimes I wouldn't have my preceptor there so it was getting them to test me and I ask questions too.

Reflection is a key ingredient in one's growth and development as a teacher and learner. In their reflections, students' remarks demonstrated key insights into their learning. Examples include:

- As I reflect on my experiences with co-teaching, both as an educator and a student, I appreciate what it can contribute to a student's learning when done effectively;

- Through personal reflection and peer/instructor feedback I have recognized both strengths and weaknesses in my educator role; and

- The peer education experience also provided me with an opportunity to reflect on some of my challenges, strengths, and beliefs about the teacher, learner, environment and knowledge.

Through their reflections, they were acknowledging what was occurring or influencing their work but also thinking about what that meant for practice. The co-teachers in the course created the opportunity and modelled the reflective process as a means of helping students to learn about their learning.

Kerridge et al. (2009) provided evidence that the role modelling by co-teachers of a professional interpersonal relationship creates a context for learning that positively influences students' own ways of thinking, analyzing and arguing. As well as an enhanced learning environment, Mislang (2011) noted that team teaching provides an example of teamwork as a core value in nursing. That is, nurses learn at the start of their career that teamwork and collaboration are vital to the profession of nursing. As students observe this dynamic in the co-taught classroom, the co-taught lesson with peers, as well as in their practicum with their preceptor, they are developing a greater understanding of the give and take and the nature of the collaboration. It is the art of collaboration that influences the outcome and the ongoing health of the co-teaching relationship. 


\section{RECOMMENDATIONS FOR EDUCATION}

Drawing on the review of the literature and the analysis of the data, four recommendations for co-teaching practice in higher education are identified and discussed. First, there is a need for greater opportunities in higher education for students to observe and experience co-teaching. As reported in this study, students appreciated the richness of the learning experience due to the diversity of perspectives that come with such a teaching approach. A rich co-teaching experience for students requires the assignment of instructors who are open and willing to work together. It is more than matching two people to teach one course. Being mindful in the conceptualization of co-teaching is needed to develop a pedagogical relationship where instructors are open to sharing their practice with a colleague. This requires administrative support and structures to help foster the development and growth of the teaching relationship.

Second, a program, department, and/or faculty that value co-teaching and its impact on student learning should see the integration of co-teaching as developing over time. This should not be something that is left for the end of a program. Rather, through curriculum mapping and elements of collaboration, peer learning and co-teaching need to be threaded throughout the program in a purposeful manner. Further, instructors may give consideration as to how they can integrate co-teaching into course assignments and provide feedback that helps build the capacity of students to be teachers and possibly co-teachers.

Third, throughout a program there is a need to design opportunities for students to practice coteaching in authentic settings. This can begin within a program by providing various learning opportunities to experience co-teaching in assignments. A suggestion is to have students co-teach in classroom and/or practice settings with junior students. This can occur in formal (e.g., classroom assignments, simulation-based learning activities) and informal settings (e.g., peer mentoring programs). Giving students the opportunity to experience and practice co-teaching helps them further develop such values and skills as problem-solving, negotiation, confidence, and resiliency.

Fourth, it cannot be assumed that instructors know how to co-teach or model effective coteaching practice to their students. Educational development needs to support co-teaching by fostering the capacity of instructors within their own context in higher education. Specific types of resources and supports can be used to develop effective strategies and techniques for successful co-teaching. Such educational development practices have to be considered both in terms of immediate, as well as sustainable actions. A suggestion is to utilize a grassroots approach where departments and/or faculties identify champions when assessing and implementing educational development needs. Educators who already use this pedagogical approach to teaching and learning have experiential knowledge that can be used to build on and inform existing co-teaching practices. Lock, Clancy, Lisella, Rosenau, Ferreira, and Rainsbury (2016) identified a co-teaching relationship as a process of change requiring self-reflection and the need to challenge one's boundaries and personal/professional identity. It is, therefore, critical to have in place supports for personal/professional enhancement of skills required to navigate through difficult situations such as courses or workshops on the art of negotiation or conflict resolution. Coteaching is also an opportunity for mentorship of novice educators (Lock et al., 2016) hence seminars focusing on developing skills in the areas of relationship building, coaching, and effective communication may be of value and can potentially mitigate some of the pitfalls when entering a coteaching relationship. 


\section{LIMITATIONS OF THE STUDY}

Three key limitations may influence the study's generalizability to other programs within higher education. First, a small number of students who participated in the study meant we were privy to a limited number of perspectives and artifacts of their learning. Second, attrition in the second part of the study (e.g., second set of individual interviews) meant we obtained limited information in terms of how the course and the co-teaching influenced their work during their capstone practicum. Third, as we reflect on our data, it has become more evident that additional questions need to be asked to further investigate the influence of co-teaching, rather than the course, on the student learning experience. Modifying the questions would have been beneficial in the study to gain a deeper understanding of the impact of co-teaching.

\section{DIRECTIONS FOR FUTURE RESEARCH}

Identified attributes of co-teaching and its impacts on nursing students are articulated in this study. What is evident from the findings, for not only nursing but also for other programs in higher education, is the need to create opportunities for co-teaching where students not only observe the practice, but also have the lived experience of co-teaching. Such opportunities and experiences open them to developing necessary understandings and skills required to practice within collaborative, complex environments. One direction for future research is to investigate the impact of co-teaching on students' self-efficacy by comparing those who had the experience of co-teaching to those who did not.

Second, another research direction is to explore positive and negative factors associated with program administration and organizational change. Co-teaching requires a shift in thinking and practice, including impacts on workload assignments, collegial relationships, and time management. With an emphasis on greater co-teaching in higher education, further exploration at the macro level is required in terms of administration and organizational structures, policies and practices.

Third, there is an opportunity to research the connection between modeling effective coteaching practice and the development of leadership skills and abilities required to engage in professional practice. Heller et al. (2004) suggested that, generally, nurses are not adequately prepared for the role of leader during their nursing education. There is evidence that leadership in nurses can be developed through educational activities, modeling and practicing leadership, and that opportunities to observe leadership skills lead to greater self-efficacy in nurses' leadership behaviors (Curtis, de Vries, \& Sheerin, 2011). Engaging in and experiencing co-teaching through educational activities in higher education may result in the cultivation of effective leadership behaviors within professional practice environments.

\section{CONCLUSION}

More so today, nurses are required to work in teams and act as educators for patients and with colleagues. To prepare them for this dynamic role in their professional programs, they must have authentic learning opportunities where they observe collaborative practice such as co-teaching and have the lived experience of this practice. This requires administrative support and planning in order to provide such opportunities for students both in courses and in health care practicum/preceptorship. What can be learned from this study is applicable to other higher education contexts that want to create co-teaching experiences that impact both instructors and students. 


\section{ACKNOWLEDGEMENTS}

This research was funded by a University of Calgary Teaching and Learning Grant.

Jennifer Lock is a Professor and the Associate Dean of Teaching and Learning in the Werklund School of Education at the University of Calgary. Her research is in online learning, ICT integration, change and innovation, and educational development in higher education.

Jacqueline Rainsbury is a research consultant and evaluator with international experience in health services research, evidencebased medicine, and public health.

Tracey Clancy is a Senior Instructor in the Faculty of Nursing at the University of Calgary. Her Master's research focused on the phenomenon of uncertainty as an embodied space of transformation for defining clinical teaching practice.

Patricia Rosenau is a retired Senior Instructor and past Associated Dean of Teaching and Learning in the Faculty of Nursing at the University of Calgary. Pat's research is focused on reflective practice and peer mentorship in nursing education.

Carla Ferreira is a tenure-track Instructor in the Faculty of Nursing at the University of Calgary. Carla holds a Master of Nursing degree with a focus on nursing education. Currently, she teaches within the undergraduate nursing program and is a faculty member in the Clinical Simulation Learning Centre.

\section{REFERENCES}

Creswell, J. W. (2012). Educational Research: Planning, Conducting, and Evaluating Quantitative and Qualitative Research (4th ed.). Boston, MA: Pearson.

Curtis, E. A., de Vries, J., \& Sheerin, F. (2011). Developing leadership in nursing: Exploring core factors. British Journal of Nursing, 20(5), 306-309.

Dumas, L. (1999). Quality perinatal nursing education through coteaching. Journal of Perinatal Education, 8(4), 27-35.

Ferguson, J. \& Wilson, J.C. (2011). The co-teaching professorship: Power and expertise in the co-taught higher education classroom. Scholar-Practitioner Quarterly, 5(1), 52-68.

Floyd, G. J. (1975). Team teaching: Advantages and disadvantages to the student. Nursing Research, 24(1), 52-56.

Heller, B. R., Drenkard, K., Esposito-Herr, M. B., Romano, C., Tom, S., \& Valentine, N. (2004). Educating nurses for leadership roles. Journal of Continuing Education in Nursing, 35(5): 203-210.

Kerridge, J., Kyle, G., \& Marks-Maran, D. (2009). Evaluation of the use of team teaching for delivering sensitive content-A pilot study. Journal of Further and Higher Education, 33(2), 93-103.

Kluth, P., \& Straut, D. (2003). Do as we say and as we do: Teaching and modeling collaborative practice in the university classroom. Journal of Teacher Education, 54(3), 228-240.

Kolb, A., \& Kolb, D. (2005). Learning styles and learning spaces: Enhancing experiential learning in higher education. Academy of Management Learning \& Education, 4(2):193-212.

Kolb, D. A. (1984). Experiential Learning: Experience as the Source of Learning and Development. New Jersey, NY: Prentice-Hall.

Kouzes, J. M., \& Posner, B. Z. (2000). Leadership Practices Inventory: Psychometric Properties. San Francisco, CA: Wiley.

Kruszewski, A., Brough, E., \& Kileen, M. B. (2009). Collaborative strategies for teaching evidence-based practice in accelerated second-degree programs. Journal of Nursing Education, 48(6), 340-342.

Laughlin, K., Nelson, P., \& Donaldson, S. (2011). Successfully applying team teaching with adult learners. Journal of Adult Education, 4O(1), 11-18.

Lock, J., Clancy, T., Lisella, R., Rosenau, P., Ferreira, C., \& Rainsbury, J. (2016). The lived experiences of instructors co-teaching in higher education. Brock Education Journal, 26(1), 22-35. 
Miles, M. B., Huberman, M., \& Saldaña, J. (2014). Qualitative Data Analysis: A Methods Sourcebook (3rd ed.). Thousand Oaks, CA: Sage.

Mislang, J. (2011). The Experiences of Undergraduate Nursing Students Enrolled in a Team Teaching Curriculum. (Unpublished Master's Thesis). University of British Columbia, Vancouver, BC.

Plank, K. M. (2011). Introduction. In K. M. Plank (Ed.), Team Teaching: Across the Disciplines, Across the Academy (pp. 1-12). Sterling, VA: Sylus.

Rytivaara, A., \& Kershner, R. (2012). Co-teaching as a context for teachers' professional learning and joint knowledge construction. Teaching and Teacher Education, 28(7), 999-1008.

Saldaña, J. (2013). The Coding Manual for Qualitative Researchers ( $2^{\text {nd }}$ ed.). Thousand Oaks, CA: Sage.

Shephard, R. J., \& Ashley, M. J. (1979). Attitudes of health science students towards teaching practices, examinations, and other related issues. Medical Education, 13, 111-116.

Wenzlaff, T., Berak, L. Wieseman, K., Monroe-Baillargeon, A. Bacharach, N., \& Bradfield-Kreider, P. (2002). Walking our talk as educators: Teaming as a best practice. In E. Guyton \& J. Rainer (Eds.), Research on Meeting and Using Standards in the Preparation of Teachers (pp. 11-24). Dubuque, IA: Kendall-Hunt Publishing.

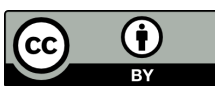

Copyright for the content of articles published in Teaching \& Learning Inquiryresides with the authors, and copyright for the publication layout resides with the journal. These copyright holders have agreed that this article should be available on open access under a Creative Commons Attribution License 4.0 International (https://creativecommons.org/licenses/by/4.0). The only constraint on reproduction and distribution, and the only role for copyright in this domain, should be to give authors control over the integrity of their work and the right to be properly acknowledged and cited, and to cite Teaching \& Learning Inquiry as the original place of publication. Readers are free to share these materials - as long as appropriate credit is given, a link to the license is provided, and any changes are indicated. 